"laid out," how it is maintained and cultivated, and what are the moral and religious lessons which arise gradually and spontaneously in a child's mind from the lessons afforded by the observation of plant-life and the habits of animals. We have no doubt of the truth of all this, but only on the condition before mentioned as to the tactful sympathy of the teacher.

\section{LETTER TO THE EDITOR.}

[The Editor does not hold himself responsible for opinions expressed by his correspondents. Neither can he undertake to return, or to correspond with the writers of, rejected manuscripts intended for this or any other part of NATURE. No notice is taken of anonymous communications.]

The Earth's Interior.

IT has long been suspected that the earth is an iron planet, and now, through the work of Strutt and others, the evidence both for and against is intensifying.

It is just worth noting, as a matter of simple arithmetic, that a core of metallic iron of density 7 , covered with a crust of rock 500 miles thick of density $2 \cdot 5$, together make up the known average terrestrial density, 5.6; but recent evidence, interestingly summarised by Principal Griffiths in his presidential address to Section A of the British Association, points to a crust much thinner than the above. It is to be hoped that the "boring " proposals of the Hon. Chas. Parsons will before long attract the attention they deserve.

Oliver LODGE.

THE EARTHQUAKE IN SOUTH AMERICA.

BETWEEN seven and eight o'clock on Thursday $B$ evening last, Valparaiso, Santiago, and many other parts of Chile were visited by a very severe earthquake, causing, it is feared, heavy loss of life and widespread damage. As was the case in San Francisco, the earthquake was followed by many outbursts of fire and the failure of the gas and electric light. According to a telegram to the New York Herald from Valparaiso, that city experienced, without any warning, the day having been unusually calm and pleasant, two distinct shocks of earthquake, and, standing as it does upon a formation of granite and gneiss, it suffered severely. The same correspondent reported the occurrence of many landslides round the city. According to Reuter, the shock at Santiago de Chile was the most severe within living memory; it lasted three and a half minutes, and was followed by heavy showers. The seismograph at the observatory was thrown out of order by the violence of the shocks, which, though slight, continued for some days.

The disturbance extended over a zone of nearly two degrees, and it is impossible at present to estimate the number of lives lost and the damage done, the accounts received being of a very conflicting nature.

The Chilian Legation in London received the following telegram from Santiago on Monday last, and the wording is in marked contrast to that found in the communications sent by Press correspondents :-

"On the evening of the I6th a severe earthquake was felt between Valparaiso and Talca. The loss of life is not very great. The damage to property is considerable at Valparaiso but less at Santiago. Public order has been entirely maintained. The authorities and private persons are succouring the distressed people, and the foreign Legations are lending their aid. The north has been wholly unaffected by the earthquake."

The earthquake was duly recorded by seismographs in different parts of the world.

The instrument at Kew Observatory plainly showed NO. I 92 I, VOL. 74] the magnitude of the disaster. The record indicated that the first tremor took place at thirty-three minutes after midnight, Greenwich time, on Friday morning. The first maximum was reached at I.2 a.m., which was followed by continuous convulsions until a second maximum was reached at 1.50 a.m.

Prof. Milne is reported to have obtained good records by means of his instruments at Shide, Isle of Wight. The first records were observed at twentyfour minutes past twelve in the morning, and from these it was known that a disaster had occurred somewhere along the western side of South America. According to Valparaiso time, it would then have been 7.15. The duration was more than five hours.

According to Reuter's correspondent at Washington, a very heavy and distinct earthquake shock was recorded on Thursday evening by the seismographs of the Weather Bureau, beginning at five minutes twenty-two seconds after seven o'clock, time of the seventy-fifth meridian. Complete and perfect records were obtained of both north to south and east to west movements of the earth's crust. The tremors were comparatively slow, and their motion was deliberate, each complete movement covering from eighteen to forty seconds.

The disturbances lasted without intermission for several hours, and finally ceased about midnight. The most violent shock seems to have occurred at fortytwo minutes twenty-six seconds after eight o'clock.

The instruments at the Hamburg Seismographic Institute are said to have shown greater and more prolonged signs of disturbance than at the time of the San Francisco disaster.

A telegram from Victoria, B.C., stated that the local seismograph recorded that the earthquake lasted four hours.

The tide gauges at Honolulu showed a disturbance, apparently of distinct origin, beginning at 5.23 a.m. on August 17. Three waves were indicated hourly, showing an oscillation of between three and four inches from the normal tides. Wireless reports from Maui and Hilo state that a wave 5 feet high occurred there. It manifested itself by an unprecedentedly heavy surf. In the enclosed Bay of Maalaea, on the island of Maui, the wave reached a height of I2 feet.

News has been received in New York that the earthquake has destroyed the island of Juan Fernandez (made famous by its supposed connection with Defoe's "Robinson Crusoe"), which was used as a Chilian penal settlement.

A despatch from Fort de France, Martinique, reports that earthquake shocks of varying severity were experienced on the island at I.I5 p.m. on August 19 and at 3.47 a.m., 4 a.m., and 8.37 a.m. on August 20 , but that no damage was done; and a Reuter telegram from Lima states that Valparaiso was visited by another heavy earthquake on the night of Monday last: also that slight shocks were felt at Lima and Huacho on that day.

\section{PROF, BROUARDEL.}

W $7 \mathrm{E}$ regret to record the death of Prof. Paul Brouarde1, of Paris, who died on July 23 at the age of sixty-nine years. Prof. Brouardel had held a large number of most important positions in the University of Paris and in the official life of France, and he had many friends in England in connection with the important work in legal medicine and in hygiene which he had done.

He was born in St. Quentin in 1837 , and received his early education at the Lycée St. Louis, in Paris. In 1859 he was an interne at the hospitals; he took 